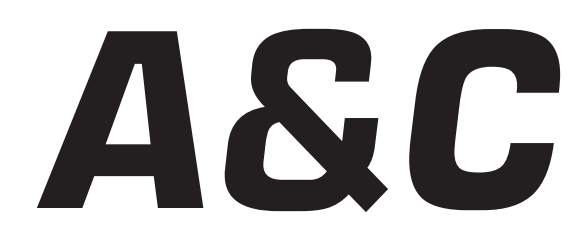

Revista de Direito Administrativo \& Constitucional

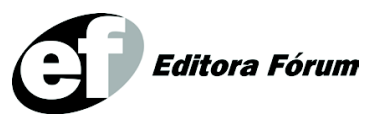

ISSN 1516-3210 


\section{A\&C REVISTA DE DIREITO ADMINISTRATIVO E CONSTITUCIONAL}

IPDA

Instituto Paranaense

de Direito Administrativo

Direção Geral

Romeu Felipe Bacellar Filho

Direção Editorial

Paulo Roberto Ferreira Motta

Direção Executiva

Emerson Gabardo

Conselho de Redação

Edgar Chiuratto Guimarães

Adriana da Costa Ricardo Schier

Célio Heitor Guimarães

\section{Conselho Editorial}

Adilson Abreu Dallari

Alice Gonzáles Borges

Carlos Ari Sundfeld

Carlos Ayres Britto

Carlos Delpiazzo

Cármen Lúcia Antunes Rocha

Celso Antônio Bandeira de Mello

Clèmerson Merlin Clève

Clóvis Beznos

Enrique Silva Cimma

Eros Roberto Grau

Fabrício Motta

Guilhermo Andrés Muñoz (in memoriam)

Jaime Rodríguez-Arana Muñoz

Jorge Luís Salomoni

José Carlos Abraão
José Eduardo Martins Cardoso
José Luís Said
José Mario Serrate Paz
Juan Pablo Cajarville Peruffo
Juarez Freitas
Julio Rodolfo Comadira
Luís Enrique Chase Plate
Lúcia Valle Figueiredo
Manoel de Oliveira Franco Sobrinho
(in memoriam)
Marçal Justen Filho
Marcelo Figueiredo
Márcio Cammarosano
Maria Cristina Cesar de Oliveira

Nelson Figueiredo

Odilon Borges Junior

Pascual Caiella

Paulo Eduardo Garrido Modesto

Paulo Henrique Blasi

Paulo Neves de Carvalho (in memoriam)

Paulo Ricardo Schier

Pedro Paulo de Almeida Dutra

Regina Maria Macedo Nery Ferrari

Rogério Gesta Leal

Rolando Pantoja Bauzá

Sérgio Ferraz

Valmir Pontes Filho

Yara Stropa

Weida Zancaner

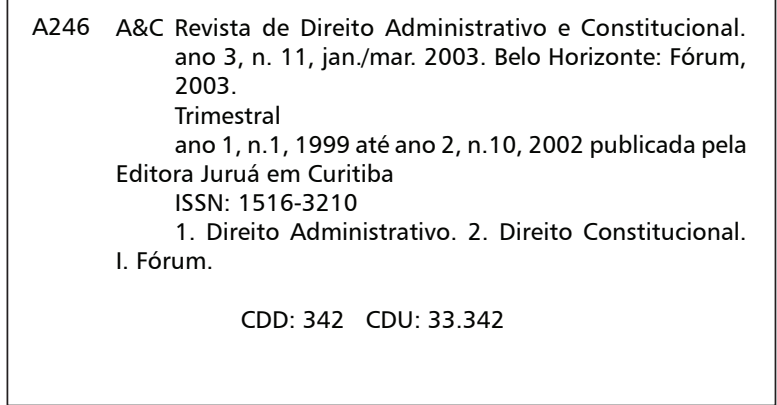

(C) Editora Fórum Ltda. 2007

Todos os direitos reservados. É proibida a reprodução total ou parcial, de qualquer forma ou por qualquer meio eletrônico ou mecânico, inclusive através de processos xerográficos, de fotocópias ou de gravação, sem permissão por escrito do possuidor dos direitos de cópias (Lei nº 9.610, de 19.02.1998).

Editora Fórum Ltda

Av. Afonso Pena, 2770 - 15\%16ª andar - Funcionários

CEP 30130-007 - Belo Horizonte/MG - Brasil

Tel.: 08007043737

Internet: www.editoraforum.com.br

e-mail: editoraforum@editoraforum.com.br
Editor responsável: Luís Cláudio Rodrigues Ferreira Projeto gráfico e diagramação: Luis Alberto Pimenta Revisora: Olga M. A. Sousa

Pesquisa jurídica: Fátima Ribeiro - OAB/MG 74868

Bibliotecária: Alessandra Rodrigues da Silva CRB 2778/MG 6 ${ }^{\text {a Região }}$

Os conceitos e opiniões expressas nos trabalhos assinados são de responsabilidade exclusiva de seus autores.

Impressa no Brasil / Printed in Brazil

Distribuída em todo Território Nacional 


\title{
O Direito-Narciso - Nova ameaça à jusfundamentalidade dos direitos
}

\author{
Vanice Lírio do Valle* \\ Doutora em Direito pela Universidade Gama Filho. Mestre em Direito pela Universidade Estácio \\ de Sá. Procuradora do Município do Rio de Janeiro.
}

Palavras-chave: Direitos fundamentais. Cidadania. Auto-suficiência do sistema constitucional de direitos fundamentais.

Sumário: 1 Introdução - 2 O Direito-Narciso, ou a pretensão de auto-suficiência como nova ameaça aos direitos fundamentais - 3 O Direito-Narciso e as distorções de sua imagem na água - 4 O Direito-Narciso reencontrando sua ninfa: a cidadania - Referências

\section{Introdução}

A proclamação vitoriosa dos movimentos revolucionários na América e Europa em favor dos direitos fundamentais e sua consagração constitucional, não tinha, decerto, como antecipar fosse aquele momento, menos a conclusão de uma conquista histórica, e mais o início de uma caminhada, que se prolongaria atravessando os séculos subseqüentes.

Convertem-se assim, as afirmações lançadas na Declaração de Direitos do Homem — dos direitos à liberdade, propriedade, segurança e resistência à opressão como naturais e imprescritíveis; do assento na Nação do princípio da soberania, e tantas outras - em pontos de partida para uma nova reflexão quanto à extensão e alcance do que sejam os aludidos direitos, e quanto à forma pela qual eles se devam relacionar com o Estado, particularmente aqueles que vieram a se organizar como Estado de Direito.

Ultrapassada a fase em que às constituições se reconhecia basicamente o papel de estruturação da organização política do poder, e assumido o compromisso valorativo desses diplomas para com os direitos fundamentais, têm-se todo o deflagrar de uma nova etapa reflexiva, em que à consagração em si dos mencionados direitos nos Textos Fundamentais, se associa a preocupação em conferir-lhes um conjunto de garantias que lhes protejam, efetivamente, o exercício, como já advertia Bobbio. ${ }^{1}$

Constitucionalizam-se, assim, direitos fundamentais, garantindolhes a observância através de sofisticados mecanismos jurisdicionais de

\footnotetext{
*E-mail: <liriodovalle@uol.com.br>.

BOBBIO. A era dos direitos, p. 24
}

A \& C R. de Dir. Administrativo e Constitucional, Belo Horizonte, ano 7, n. 28, p. 27-44, abr./jun. 2007 
controle, que se desenvolvem através de uma intensa atividade interpretativa, seja pelas Cortes Constitucionais, seja pelas estruturas supranacionais destinadas a essa mesma finalidade, como a Corte Européia de Direito Humanos, o Tribunal de Justiça das Comunidades Européias, ${ }^{2}$ a Corte Interamericana de Direitos Humanos e mesmo o Tribunal Penal Internacional.

O processo, porém, está longe de se completar: é de Ordóñez Solís ${ }^{3}$ a advertência de que a cooperação internacional e a integração supranacional, por sua vez, reclamam também a consolidação do poder do juiz na proteção dos direitos fundamentais, a ponto de afirmar se apresentem esses como uma das dimensões constitucionais do direito internacional contemporâneo.

O direito brasileiro, por sua vez, não restou isolado desse movimento mundial. Assim, por ocasião da Constituição de 1988, o tema dos direitos fundamentais se apresenta como prioridade constitucional não só do ponto de vista topográfico, com seu deslocamento para a abertura do Texto Fundante; mas também através de uma série de outros indicativos como a afirmação de sua aplicação imediata (art. $5^{\circ}, \S 1^{\circ}$ da CF); a amplitude do elenco normatizado, com a inclusão de direitos sociais (art. $6^{\circ}$ da CF) e ainda de vetores como a solidariedade e a fraternidade (arts. $3^{\circ}, 194$ e 195 da CF, v.g.); a abertura a outros direitos decorrentes de regimes e princípios constantes de tratados internacionais em que o Brasil seja parte (art. $5^{\circ}$, $\S 2^{\circ}$ da CF), etc.. A opção constituinte não foi tópica, mas sistêmica. Não foi igualmente, momentânea, mas se reafirma, como mais recentemente, com a submissão à jurisdição do Tribunal Penal Internacional (art. $5^{\circ}, \S^{\circ}$ da CF) e a equivalência a emendas constitucionais aos tratados e convenções internacionais sobre direitos humanos que se venha a aprovar (art. $5^{\circ}, \S 3^{\circ}$ da CF); ambas providências empreendidas pela EC no $45 / 2004$.

Se de um lado, essa proclamação pelo direito brasileiro de seu compromisso com a jusfundamentalidade dos direitos humanos nos alinha com as cogitações empreendidas pelas nações mais modernas; de outro lado, a nossa extensa rede - enunciada — de proteção aos direitos fundamentais por vezes se apresenta potencializadora de riscos sociais e democráticos, na medida em que pode gerar uma espécie de repre-

\footnotetext{
2 Registre-se que, em relação ao TJCE, a tutela de direitos fundamentais se dá pela via reflexa, da exigência de observância, pelos Estados-Membros, das normas atinentes ao direito comunitário - muitas das quais versam também sobre a jusfundamentalidade de direitos.

3 ORDÓÑEZ SOLís. La protección judicial de los derechos fundamentales de solidariedad: derecho sociales, medio ambiente y consumidores, p. 15.
} 
sentação apaziguadora de um enfrentamento amplo e eficaz do tema pelo Estado-Poder. ${ }^{4}$

Esse é o ponto que se desenvolve brevemente nessas considerações, a título de provocação a um olhar crítico — que se entende deva ser recorrente - em relação aos limites e possibilidades do direito em matéria tão sensível. Para tanto, a par da explicitação dos perigos da ilusão da autosuficiência; o texto explora os riscos da subversão do bem da vida pretendido proteger através do discurso da jusfundamentalidade, em razão da insuficiência do ferramental exclusivamente jurídico para o enfrentamento das complexidades inerentes ao tema.

\section{O Direito-Narciso, ou a pretensão de auto-suficiência como nova ameaça aos direitos fundamentais}

Constitui verdadeiro truísmo a afirmação de indissociabilidade entre direito e poder, o primeiro com pretensões reguladoras do segundo, naquela estrutura que se denominou Estado de Direito, nas suas sucessivas manifestações e aprofundamentos. É de Peña Freire ${ }^{5}$ a síntese da tarefa a que, a rigor, se propunha ainda a esse Estado subordinado ao Direito, sob o ponto de vista axiológico: "Ésta no es outra que la afirmación da primazia de lo personal y social en las relaciones con el poder". ${ }^{6}$

Reconhecida a importância crescente da limitação do poder político, tendo em conta todavia elementos estruturantes dessa mesma organização estatal - notadamente, os direitos fundamentais -, tem-se a consolidação de uma moldura teórica consagradora da Constituição como materialização das premissas valorativas de operação do Estado, e da democracia substantiva; como mecanismo de concretização desses mesmos propósitos. Adentra-se portanto ao período do neoconstitucionalismo, em que, na lição de Pozzolo, ${ }^{7}$ o direito constitucional positivo teria por característica uma projeção evolutiva, expansiva e necessária, de seu conteúdo para o direito do dia-a-dia; que qualifica como jurídico um sistema normativo, pelo conteúdo de justiça que ele venha a expressar.

\footnotetext{
4 Veemente advertência em relação ao caráter potencialmente simbólico dos direitos humanos nos faz Neves (2005), destacando sirva essa força à "... afirmação e realização generalizada de direitos relacionados com a inclusão jurídica em condições de dissenso estrutural..", e ainda à já mencionada retórica destinada a encobrir as carências em relação a esses mesmos direitos (NEVES. A força simbólica dos direitos humanos. Revista Eletrônica de Direito do Estado).

5 PEÑA FREIRE. La garantia en el Estado constitucional de derecho, p. 54.

6 Destaque-se de já a complexidade de uma tarefa enunciada de forma aparentemente tão simples, na medida em que o pessoal e o social, muitas vezes, já guardam entre si incompatibilidades; que dirá o social que congrega no seu interior, o pluralismo e o multiculturalismo, como hoje é a tônica.
} 
Se do ponto de vista teórico, essas construções se afiguram logicamente conexas; no plano da realidade da vida elas partem de - para usar a expressão de Canotilho ${ }^{8}$ — “...uma má utopia do sujeito projectante...”, na medida em que “...ergueram ao Estado como 'homem de direção' exclusiva ou quase exclusiva da sociedade, e converteram o direito em instrumento funcional dessa direcção...”. Antes disso, porém, a pretensão de se reconhecer ao direito, na consagração dos direitos fundamentais, essa função de articulação subordinante das várias manifestações, esferas e agentes do poder, importa em uma profissão de fé sua capacidade de, pela enunciação normativa, mobilizar por si só os vetores necessários à efetivação desses mesmos direitos. É nesse aspecto que se alude a um direito narcisista.

Narciso, filho do deus-rio, famoso por sua beleza e orgulho, era cortejado por admiradores diversos, sem que se sensibilizasse pelo assédio de qualquer deles. Nem mesmo a ninfa Eco, que por ele se apaixonou, foi capaz de despertar a atenção de Narciso, que culmina por se enamorar por sua própria imagem refletida no rio, a ponto de se esquecer de tudo mais à sua volta, identificando dissociando essa imagem da sua própria realidade, elegendo-a como sujeito de seu amor.

Assim parece caminhar o discurso dos direitos fundamentais, encantado com a própria figura, permitindo baixar uma névoa de opacidade sobre as condições à sua volta, e ainda repudiando ou ignorando outros atores que, habitando o mundo dos homens, desejam ou precisam com o Direito-Narciso encontrar interação.

Manifestação desse narcisismo jurídico que vivemos é a pretensão de auto-suficiência do sistema constitucional de direitos fundamentais, que almeja encontrar na sua própria imagem - direito - refletida no espelho d'água, o grande, se não o único objeto merecedor de atenção. A referência se faz ao fato de que, diante dos desafios atinentes à concretização dos direitos fundamentais, oferece o Direito-Narciso como resposta, um elenco de medidas jurídico-processuais, que teriam supostamente o condão de superar os impasses de efetividade.

O texto da Carta de 1988, a par de enunciar garantias jurisdicionais já consagradas como a ação popular, o habeas corpus e o mandado de

\footnotetext{
POZZOLO. Un constitucionalismo ambiguo. In: CARBONELL, Miguél. (Ed.). Neoconstitucionalismo(s), p. 259-278.

8 CANOTILHO. Romper ou rever com a constituição dirigente. In: __. "Brancosos" e interconstitucionalidade: itinerários dos discursos sobre a historicidade constitucional, p. 101-129.
} 
segurança; cria ainda novas figuras como o mandado de injunção (individual e coletivo), o habeas data, a argüição de descumprimento de preceito fundamental, a ação abstrata de controle de inconstitucionalidade por omissão, além de constitucionalizar à ação civil pública e abrir ainda a possibilidade de impetração de mandado de segurança de caráter coletivo. ${ }^{9}$ O suposto é de que se pode solucionar os eventuais déficits de efetividade da afirmação jurídica de direitos fundamentais, com a enunciação não menos jurídica, de instrumentos de solução jurisdicional do problema — “...é que Narciso acha feio o que não é espelho...”, já dizia Caetano Veloso.

Mas a realidade não tem complacência com o Direito-Narciso, e vai evidenciar o impasse a que ele é conduzido à conta de seu enamoramento por si mesmo. Essa dissociação entre Direito-Narciso, essência - a saber, os direitos fundamentais que ele proclama - e a imagem de autosuficiência que ele projeta e por quem se enamorou, se expressa inicialmente a partir da desqualificação, pela realidade da vida, das categorias com que inicialmente se operava no equacionamento do desafiante tema da sua efetividade.

Primeira manifestação da insuficiência das enunciações categoriais do direito é o esgarçar de velhas distinções como aquela proposta entre direitos fundamentais de liberdade e direitos fundamentais sociais. Essa pretensa diferenciação, que tanto se invocou em atenção a uma tendência classificatória que é própria do direito, se utilizava e utiliza ainda para o enfrentamento de tormentosos temas atinentes à efetividade dos direitos fundamentais, notadamente o da escassez de recursos. Cada vez mais, todavia, o espelho, refletindo a imagem de Narciso se mostra insuficiente a reproduzir todas as sutilezas do problema.

Já no paradigmático The cost of rights, Holmes e Sunstein ${ }^{10}$ evidenciavam que a qualificação como direitos de liberdade não autorizava a compreensão de que fossem esses imunes a custo. ${ }^{11}$ Abramovich e Courtis, ${ }^{12}$ por sua vez, destacam a falácia de uma associação entre direitos de liberdade e obrigações negativas de parte do Estado, e de outro lado, direitos sociais e obrigações de conteúdo prestacional, na medida em que o conteúdo variável e em expansão dos chamados direitos de liberdade pode estar a exigir para sua efetiva garantia, mais do que o simples inagir

\footnotetext{
9 Servindo igualmente à preservação do Texto Fundante - e por via reflexa, aos compromissos axiológicos que nele se contém - é possível ainda apontar a própria ação abstrata de controle de inconstitucionalidade, e sua co-irmã, a declaratória de constitucionalidade, essa última originária da Emenda Constitucional $n^{\circ} 3$.

${ }^{10}$ HOLMES, Stephen; SUNSTEIN, Cass. The cost of rights: why liberty depends on taxes.
} 
do Poder. Fleiner-Gerster, ${ }^{13}$ por outro lado, adverte para a importância da avaliação das condições econômicas e sociais dadas para identificar qual seja, efetivamente, o conteúdo dos direitos fundamentais como tarefas conferidas à ordem estatal.

De tudo isso resulta - e a enunciação foi meramente exemplificativa - que a classificação empreendida pelo Direito-Narciso se revela contraditada pela realidade da vida, em que o clássico direito à liberdade de expressão pressupõe o já mais moderno e complexificado acesso à informação, ${ }^{14}$ que, por sua vez, demanda muito mais do que uma simples abstenção da estrutura formal de poder político. Nesse compasso, em verdade, o espelho se torna prisão, reduzindo a imagem construída sob a ótica narcisista a muito menos do que aquilo que a realidade efetivamente propõe.

Segunda manifestação da insuficiência do direito para a adequada compreensão e tratamento dos direitos fundamentais é a sua dificuldade na identificação de que esse é um tema de matriz coletiva, e que a sua tutela só será efetiva se construída a partir dessa mesma perspectiva.

Aqui uma vez mais trai ao Direito-Narciso a sua própria imagem auto-referenciada, mais afeita à lógica da composição do conflito intersubjetivo; do esquema ordenador autor-réu, credor-devedor, e que tem dificuldades no convívio das pretensões eventualmente conflitantes de grupos diferenciados.

Pluralismo e convívio dos múltiplos é para o direito ainda um desafio de compreensão - e certamente, de equacionamento; e com isso, Narciso segue examinando o problema da efetividade dos direitos fundamentais sem os benefícios que poderia extrair das ninfas Eco que o circundam, e que desejam ardentemente a interação. A referência é a outras áreas do conhecimento, que exigem articulação com o direito, como a sociologia, a antropologia, a política, a ética, e tantas outras; boa parte delas forjadas

\footnotetext{
${ }^{11}$ A mesma idéia - embora não seja a cogitação central do trabalho - se identifica em trabalho mais recente de Sunstein, ao asseverar que o adequado exercício da liberdade de expressão pressupõe, no labor interpretativo da Suprema Corte Americana, um direito de acesso do falante a lugar e pessoas próprias ao exercício dessa mesma liberdade; assim como a garantia pelo Poder Público, dos investimentos necessários à garantia dessa mesma possibilidade de acesso (SUNSTEIN. Republic.com, p. 28).

12 ABRAMOVICH; COURTIS. Los derechos sociales como derechos exigibles, p. 24.

${ }^{13}$ FLEINER-GERSTER. Teoria geral do Estado, p. 118.

${ }^{14} \mathrm{Em}$ tempos de sociedade do conhecimento, de articulação de issue networks e da indispensabilidade de mecanismos de filtragem e crítica do caudaloso fluxo de dados de todas as matizes, indiscutível o caráter expansivo do conteúdo do velho direito à informação (HECLO. Issue networks and the executive establishment. In: THEODOULOU, Stella Z.; CAHN, Matthew A. Public policy: the essential readings, p. 46-58).
}

A \& C R. de Dir. Administrativo e Constitucional, Belo Horizonte, ano 7, n. 28, p. 27-44, abr./jun. 2007 
a partir de um fundamento de sensibilidade para o coletivo, para as conciliações possíveis empreender nesse nível, em que nem sempre o consenso será a única alternativa, mas também o trade-off, ou mesmo a admissão pura e simples de diferenças intrínsecas que justifiquem e legitimem tratamentos diferenciados, inclusive juridicamente. ${ }^{15}$

Fato é que o direito passou do isolacionismo fundado no discurso de um imperativo de pureza técnica que se centrava no normativismo, para uma postura ainda insular, que a partir de sua profissão de fé nos valores, determina um excesso de autoconfiança; uma pretensão de auto-suficiência que a complexidade da sociedade moderna não autoriza mais. ${ }^{16}$

A constitucionalização fundamental da sociedade, na expressão de Canotilho ${ }^{17}$ pretende que os problemas econômicos e sociais sejam “...simultaneamente, problemas constitucionais susceptíveis de conformação e resolução através de decisões político-constitucionais vinculativas das decisões tomadas pelo poder político..." - e a realidade insiste em evidenciar que o enclausuramento das questões, encoberto por uma homilia de diferenciação funcional, conduz à inefetividade do discurso constitucional, e ao comprometimento da credibilidade da Constituição. ${ }^{18}$

É em reação a essa ameaça de credibilidade que se impõe a quebra do narcisismo, e a recuperação da aproximação entre o direito, e os demais vetores que necessariamente envolvem o equacionamento de suas manifestações que se revistam, a um só tempo, de fundamentalidade e coletividade. A consideração, portanto, de implicações políticas, econômicas, sociais e mesmo culturais das alternativas de composição do conflito envolvendo - por exemplo - a direitos sociais, destaca Faria, ${ }^{19}$ é o caminho para o alinhamento do direito no sentido da consecução de “...um princípio de balanceamento de interesses irredutíveis a uma medida universal e geral...”.

Se essa imperatividade de aproximação do direito com as demais

\footnotetext{
15 Afinal, se a desigualdade se põe como premissa, o tratamento jurídico como iguais serviria, na verdade, à não-isonomia.

${ }^{16} \mathrm{Não}$ é ocioso o registro de que mesmo entre os teóricos do direito como sistema autopoiético o isolamento cognitivo absoluto em relação ao ambiente é defendido ou valorizado: "...o encerramento do sistema jurídico - como de todo e qualquer outro sistema comunicacional autopoiético - é um 'encerramento operativo', perfeitamente compatível com uma abertura e uma dependência ambiental." (CLAM. A autopoiese no Direito. In: ROCHA, Leonel Severo; SCHWARTZ, Germano; CLAM, Jean. Introdução à teoria do sistema autopoiético do direito, p. 87-145).

${ }^{17}$ CANOTILHO, J. J. Gomes. Estado pós-moderno e constituição sem sujeito. In: __ . "Brancosos" e interconstitucionalidade: itinerários dos discursos sobre a historicidade constitucional, p 131-162.

${ }_{18}$ Nesse sentido, consulte-se SARMENTO, Daniel. Direitos fundamentais e relações privadas. Rio de Janeiro: Lúmen Juris, 2004, p. 73-74.
} 
ciências já se evidenciava no terreno da investigação dos supostos deveres do Estado, com maior razão se terá por impositiva quando se cogita dos direitos que envolvam aos vetores da solidariedade e fraternidade, em que a atuação substitutiva por parte das estruturas de poder não será possível, ou quando menos, não se revelará a constitucionalmente desejada.

É preciso que Narciso veja além do espelho, que mais do que reducionista — na medida em que exclui da imagem uma parte importante do cenário - pode em verdade, se revelar enganoso.

\section{O Direito-Narciso e as distorções de sua imagem na água}

Enunciado no texto constitucional um largo espectro de direitos fundamentais, todos sob o signo da aplicabilidade imediata, tendo a si ainda associados instrumentos jurisdicionais diversos destinados à sua garantia, o que se tem como conseqüência natural é o incremento da judicialização desses mesmos temas. ${ }^{20}$ Não menos natural, é que com a redemocratização do País - a essa altura, já consolidada, inclusive com o teste de resistência de um impeachment de um Presidente eleito - seja menos freqüente a reivindicação dos direitos fundamentais de liberdade, já mais incorporados pelo discurso e pelo agir do poder político formal; restando, portanto, como prioridade no debate judicial, a exigência dos chamados direitos fundamentais de segunda geração. ${ }^{21}$

Já nesse terreno, manifestam-se as insuficiências do esquema lógicoracional do direito, que tem enormes dificuldades em traçar uma moldura compreensiva em relação ao fato de que, em matéria de direitos fundamentais sociais, é de se reconhecer não só a projeção na esfera de direitos individuais de um eventual jurisdicionado, mas também a dimensão do coletivo que pretende assegurar essa mesma declaração de direito. $\mathrm{Na}$ verdade, cuida-se de promover — na lição de Goyard-Fabre ${ }^{22}$ — a superação dos egoísmos individuais, para na ordem objetiva das instituições que o direito constrói, projetar a aspiração da razão ao universal.

\footnotetext{
${ }^{19}$ FARIA. Introdução: o Judiciário e o desenvolvimento sócio-econômico. In: (Org.). Direitos humanos, FARIA. Introdução: o Judiciário e
direitos sociais e justiça, p. 11-29.

20 Em recente declaração ao jornal O Globo, publicada na seção "O País", edição do dia 20 de março de 2007, a Presidente do Supremo Tribunal Federal (STF), Ministra Ellen Gracie, disse que o volume de processos no Brasil tornou-se praticamente impossível de ser analisado. São 62 milhões de processos que tramitam no país, 4.400 casos para cada magistrado. O modelo atual, segundo a Ministra, estimularia o litígio.

${ }^{21}$ É de Barbosa Moreira advertência de que esse aumento da conflituosidade se relaciona à "...incessante expansão da área em que a Justiça é chamada a atuar...", destacando temas antes entendidos como reserva da Administração, e hoje submetidos à apreciação jurisdicional, como proteção ao consumidor e meio ambiente (BARBOSA MOREIRA, José Carlos. O problema da duração dos processos: premissas para uma discussão séria. Revista Magister de Direito Civil e Processual Civil, p. 27-36).
} 
Não equacionadas na sua relação intrínseca essas duas manifestações possíveis daquilo que se denomina direito fundamental social, a conseqüência é a não distinção por parte da jurisdição, dessas duas distintas órbitas de atuação desses mesmos direitos - e disso pode resultar uma apropriação indevida do discurso da jusfundamentalidade, que transforme a judicialização num mecanismo apaziguador do corpo social e da classe política; e ainda de esvaziamento da cidadania.

É certo que o direito brasileiro conhece - e de há muito - a categoria dos direitos coletivos, normatizada antes mesmo da Carta de 1988, através da Lei $\mathrm{n}^{\circ} 7.347 / 85$, que disciplinando a ação civil pública, elege como seu objeto possível a tutela de direitos e interesses difusos ou coletivos. A preocupação com a tutela de direitos coletivos lato sensu, e a oferta de respectivas vias de ação se viu igualmente na Constituição Federal com a institucionalização do mandado de segurança coletivo; a elevação da civil pública a status constitucional, e ainda a instituição de mecanismos de controle de constitucionalidade que, construídos a partir da apreciação objetiva, se aproximam igualmente da tutela de um direito que transcende à esfera individual de relevância.

Não é menos certo porém que esse vasto leque de instrumentos jurisdicionais ainda claudica no que toca a importantes questões já equacionadas em sistemas alienígenas, de maior tradição da reivindicação coletiva. Assim é que o conceito de representação adequada para fins de manejo de ações coletivas, a possibilidade da conversão da demanda individual em coletiva, e tantas outras questões relevantes atinentes à maximização dos efeitos desse instrumento jurisdicional são temas ainda não incorporados ao sistema brasileiro. ${ }^{23}$

Das deficiências do sistema processual de tutela de direitos coletivos — e do déficit de atendimento, pelo Estado, dos direitos sociais em relação aos quais se viu comprometido pelo texto constitucional - decorre a freqüente utilização das vias de ação destinadas à tutela de direitos individuais, para a preservação em favor do autor, do direito fundamental apontado como violado. E essa estratégia culmina por gerar grandes distorções - uma vez mais sem que o Direito-Narciso, encantado com

\footnotetext{
22 GOYARD-FABRE, Simone. Os princípios filosóficos do direito político moderno, p. 354-355.

${ }^{23}$ Nesse sentido já advertia Mendes, sublinhando que "...a existência de várias ações coletivas, ao lado de milhares de feitos individuais versando sobre a mesma questão de fundo, coloca em descrédito a perspectiva de um processo verdadeiramente coletivo, concebido para concentrar em um único feito as decisões, colheitas de provas, recursos e, eventualmente, a própria execução" (MENDES. Ações coletivas no direito comparado e nacional, p. 272).
} 
o seu reflexo nas águas, consiga enxergar os verdadeiros resultados no âmbito da sociedade.

Primeiro aspecto que merece destaque é que a predominância do recurso às demandas individuais como o caminho mais comum para a persecução da tutela de direitos sociais - que conceitualmente, são de cunho coletivo - ; a um só tempo encobre o imperativo de que as soluções hão de ser conferidas tendo em conta essa específica matriz; e ainda favorece àqueles que com maior facilidade, podem, por seus próprios meios, se valer do Poder Judiciário. Assim, em que pese se cuide de manifestação de direito social - e portanto, de repercussão em todo um segmento da sociedade - temas como o direito à saúde ou à educação, no mais das vezes são examinados no bojo de uma demanda individual, que por fatores próprios àquele demandante, podem alcançar mais rapidamente ao Judiciário, ou a seus órgãos de cúpula para fins de obtenção de uma decisão de cunho definitivo, ou associada a mecanismos expressivos de coercitividade.

Nisso reside a mencionada apropriação indevida do discurso dos direitos fundamentais. E se diz indevida a apropriação, porque ele se tem por veiculado não em favor da sociedade como um todo - mas da projeção na esfera de direitos individuais de um determinado demandante -; e a tutela jurisdicional que eventualmente ali se venha a conferir pode estar a priorizar não o mais carente de proteção estatal, detentor de uma preferência constitucional que exsurge dos princípios enunciados nos arts. $1^{\circ}$ e $3^{\circ}$ da CF, mas sim aquele que aos meios de coerção jurisdicional tem mais fácil acesso.

Outro efeito deletério possível dessa mesma apropriação indevida é a determinação pelo Judiciário, de medidas pontuais que venham a conferir em si, pelo reflexo que possam ter na complexa rede de políticas públicas, um comprometimento de outras esferas de atuação do Poder Público, igualmente concretizadoras de compromissos sociais. Afinal, as políticas públicas - atualmente, eleitas como virtual objeto de controle jurisdicional para fins de garantia de efetividade de direitos fundamentais - se relacionam de forma matricial, e a interferência, decorrente de decisão individual ou coletiva, na política "A" pode significar o absoluto comprometimento das possibilidades de implementação da política "B". Com isso, no balanço final, se pode ter, em nome da tutela jurisdicional a um determinado particular (ou mesmo grupo), a imposição de uma 
situação desfavorável, do ponto de vista de tutela de direitos fundamentais, a um grupo muito mais significativo, pelos efeitos reflexos da ordem judicial sobre a política pública de que esses últimos sejam beneficiários.

Intimamente associada a essa apropriação indevida do discurso dos direitos fundamentais está o equívoco decorrente da representação pacificadora de sua tutela, decorrente da outorga de prestação jurisdicional em favor de um determinado demandante - na verdade, essa é a contraface, no âmbito do Judiciário, da mesma patologia. E isso se diz, porque o magistrado, provocado à tutela de um direito social (que conceitualmente, tem dimensão coletiva), não dispondo de técnicas e instrumentos próprios a conferir essa mesma dimensão ao litígio que tem a si submetido, culmina por decidir nos limites do que está posto, afirmando que assim o fazendo, está a tutelar direitos fundamentais - quando na verdade, o que se faz é o equacionamento (meritório, é verdade) da simples projeção na esfera de direito individual de um único cidadão.

O risco inerente a essa situação — é importante enfatizar — não decorre propriamente, da satisfação (ainda que em caráter estritamente individual) de um direito que se classifica como social. Afinal, tal providência, embora não se revele suficiente à proteção do valor de que efetivamente cogitava a Constituição - garantia à coletividade — caminha na mesma direção no que toca aos resultados perseguidos. $O$ perigo reside em que a multiplicação dessas mesmas providências tópicas determine, de um lado, a formação de prioridades segundo um critério de simples antecedência no alcance do Judiciário (que certamente, não é de inspiração constitucional), como já mencionado; e de outro lado, de que a subversão pacificadora a que já se teve oportunidade de referir, gere um sentimento de desnecessidade de aplicação de engenho criativo na retomada dos possíveis caminhos de solução na trilha da tutela efetivamente coletiva.

No terreno da cunhagem de prioridade a partir da precedência no acesso ao Judiciário, é possível apontar, a título de exemplo, precedentes que no campo do direito à saúde, extravasam o terreno da sua garantia ao hipossuficiente, para afirmar assegurar tutela jurisdicional variada desde que o enfrentamento das despesas decorrentes do tratamento seja suficiente a comprometer as condições originais de sustento do paciente e de sua família. ${ }^{24}$ Repita-se, por mais meritória que possa se revelar a proteção

A \& C R. de Dir. Administrativo e Constitucional, Belo Horizonte, ano 7, n. 28, p. 27-44, abr./jun. 2007 
jurisdicional na hipótese concreta, fato é que ela se limita à garantia da projeção na esfera de direitos do jurisdicionado, daquilo que a Constituição quis assegurar à coletividade, postergando e encobrindo uma discussão muito mais delicada, qual seja, aquela atinente ao controle jurisdicional da existência real de uma política consistente e em desenvolvimento, no sentido da tutela desse mesmo direito ${ }^{25}$ — a esse tema se retornará no título abaixo.

Do cunho quase ilusionista do uso dos instrumentos individuais no tratamento dos direitos fundamentais — por definição, coletivos — também nos dá exemplo a casuística jurisprudencial, em que a enunciação da providência jurisdicional outorgada é de controle de políticas públicas (o que inegavelmente está a sugerir uma dimensão transindividual, quando na verdade o que se empreende é à composição de eventual violação de direitos na sua projeção na esfera individual. ${ }^{26}$ Mas outras são as distorções que a propagação de ondas no espelho d'água pode trazer à auto-imagem do Direito-Narciso. Cumpre agora destacar aquela decorrente da abdicação, pelo próprio direito, do potencial de sua atuação como controlador do agir do poder.

Embora - e sobre isso já se aludiu no título 2 desse trabalho integre a pretensão de auto-suficiência do Direito-Narciso as respostas garantísticas que ele mesmo enuncia, notadamente através de uma miríade de instrumentos processuais; fato é que a prática dessas mesmas garantias

\footnotetext{
${ }^{24}$ REsp 430.526/SP. Órgão julgador: Primeira Turma. Relator: Ministro Luiz Fux. Julgado em 01 out. 2002. DJ, p. 245, 28 out. 2002. Na mesma esteira, entendendo absoluto o direito à proteção via SUS, sem qualquer limitação subjetiva, ainda os REsp. 212346 e 325337.

${ }^{25}$ Registre-se a recente decisão da Presidência do STF, Min, Ellen Gracie, em que no tema, se resgatou esse aspecto, do imperativo da atenção "... Com efeito, a gestão da política nacional de saúde, que é feita de forma regionalizada, busca uma maior racionalização entre o custo e o benefício dos tratamentos que devem ser fornecidos gratuitamente, a fim de atingir o maior número possível de beneficiários. Entendo que a norma do art. 196 da Constituição da República, que assegura o direito à saúde, refere-se, em princípio, à efetivação de políticas públicas que alcancem a população como um todo, assegurando-lhe acesso universal e igualitário, e não a situações individualizadas. A responsabilidade do Estado em fornecer os recursos necessários à reabilitação da saúde de seus cidadãos não pode vir a inviabilizar o sistema público de saúde" (STA 91/AL. Relatora a Min. Presidente, Ellen Gracie, publicado em 5 de março de 2007).

${ }^{26}$ Consulte-se, no tema, o Agravo Regimental interposto da decisão lançada no Recurso Extraordinário $n^{\circ}$ 410.715 e no 436996, Relator o Min. Celso de Mello, em que a $2^{a}$ Turma do STF confirmou decisão monocrática original de provimento do recurso constitucional, para fins de assegurar-se o direito ao acesso à creche e pré-escola, não em favor de uma determinada coletividade — mas sim de um menor em particular, representado pelo Ministério Público. A enunciação, todavia, seja da decisão monocrática, seja do acórdão que a confirmou, aludindo ao controle de políticas públicas induz uma percepção de que o espectro de situações compreendidas na prestação jurisdicional seja muito mais amplo do que efetivamente o é. Na mesma linha, ainda as decisões monocráticas (irrecorridas) proferidas nos Recursos Extraordinários n 472.707, n 467.255, também pelo Min. Celso de Mello.
} 
jurisdicionais se distancia desse discurso de promessas. Mais freqüentemente se encontrará uma jurisprudência defensiva, apegada a velhos dogmas e pouco afeita à abertura cognitiva em relação a outros dados que não os originários do próprio direito; uma perfeita ilustração da imagem de Narciso correspondendo ao amor do Narciso real.

Os exemplos são múltiplos, mas por todos, aponte-se a estocada, ferindo quase que de morte ao sistema de controle da inconstitucionalidade por omissão, proferida pelo próprio STF, no acórdão proferido no MI 107-QO, onde de uma só vez, em nome de uma vetusta concepção de equilíbrio e harmonia entre os poderes, se sustentou que o provimento jurisdicional - a resposta do direito auto-suficiente - era a admoestação quanto ao não cumprimento das promessas constitucionais. ${ }^{27} \mathrm{Na}$ seqüência, têm-se ainda um inegável apequenamento das possibilidades da ADPF, com a imposição do signo da subsidiariedade em relação aos demais instrumentos de controle de constitucionalidade, num indicativo também veemente que no plano concreto do exercício da função jurisdicional, o discurso da auto-suficiência se vê muitas vezes contido por uma percepção da realidade de parte dos agentes julgadores, muito mais severa do que o entusiasmos teórico por vezes sugere.

Mas não é só na negação do próprio discurso de auto-suficiência que o Direito-Narciso se fragiliza. Também no que toca propriamente ao aperfeiçoamento do seu agir de controle desenvolvido através da função jurisdicional, o enclausuramento do direito em relação aos motivos determinantes da conduta (ação ou inação) controlada, já explorado em trabalho anterior, ${ }^{28}$ revela uma visão reducionista dos problemas, e uma prática não dialógica, que não contribui para a consolidação de um agir estruturado e articulado dessas mesmas estruturas de poder político-estatal.

Fato é que no momento em que os temas atinentes ao controle do agir do poder no sentido da garantia dos direitos fundamentais desembocam no Judiciário, seja pelo exercício em sentido estrito da jurisdição constitucional, seja por outros mecanismos processuais; a tendência -

\footnotetext{
27 No tema, consulte-se VALLE, Vanice Lírio do. Mandado de injunção: a construção de uma garantia constitucional. Rio de Janeiro: Lúmen Juris, 2005.

${ }^{28}$ VALLE, Vanice Lírio do. Diálogo institucional como pressuposto da efetividade constitucional. A\&C Revista de Direito Administrativo e Constitucional, p. 189-206.
} 
decorrente da tanto referida ilusão de auto-suficiência do direito — é descartar a investigação em relação aos motivos determinantes desse agir investigado, numa espécie de inversão da presunção de que a efetividade da Constituição é imperativo posto a todas as estruturas do poder. $\mathrm{O}$ direito auto-referenciado ignora à política, às finanças, a qualquer outra razão que possa ter interferido no processo decisório de outra estrutura formal de poder - Legislativo ou Executivo - e pretende por si só, superar qualquer espécie de obstáculo que possa ter se posto à materialização dos ideais constitucionais. Ocorre que no mais das vezes, a concretização das ordens jurisdicionais exigirá a interação com essas mesmas estruturas institucionais com as quais o direito aplicado, o direito-jurisdição não desejou dialogar — e as dificuldades são previsíveis.

É falsa, portanto, a imagem que Narciso projeta de si mesmo - assim, inexiste, efetivamente, o objeto de seu amor. Na lenda grega, a tentativa vã de alcance, pelo apaixonado, do suposto objeto de sua paixão, levou-o à morte. $\mathrm{E}$ a que pode conduzir esse traço narcisista de nosso sistema de direitos fundamentais?

\section{O Direito-Narciso reencontrando sua ninfa: a cidadania}

Já se mencionou nesse texto, o caráter de verdadeira representação apaziguadora dos reclamos sociais de que o nosso vasto e complexo sistema de garantia de direitos fundamentais pode se revestir. Assim é que, por solene declaração constitucional, o Brasil é um país solidário, fraterno, e que garante à dignidade da pessoa humana através de um vasto elenco de direitos fundamentais.

Se isso assim o é, e a eventual deficiência dessa afirmação constitucional na esfera individual de direitos pode ser perseguida através de uma demanda também singular - onde o discurso constitucional é reenunciado em favor de todos, mas concretizado em favor de um só o que se tem é um significativo esvaziamento do processo de participação cidadã, em dois relevantes momentos em que essa mesma interação se revelaria fundamental.

Num plano mais abstrato, essa afirmação quase autista e absolutizante de uma plêiade de direitos fundamentais — uma vez mais, a lição é de Goyard-Fabre ${ }^{29}$ — “...aniquila a autonomia da vontade...”, desvaloriza aos próprios direitos, de modo que nada mais é direito.

É importante ainda ter em conta que o caráter aberto da enunciação

A \& C R. de Dir. Administrativo e Constitucional, Belo Horizonte, ano 7, n. 28, p. 27-44, abr./jun. 2007 
de muitos dos direitos contidos no Texto Fundante pode decorrer inclusive - como leciona Sunstein - de uma teorização insuficiente. Essa ausência de teorização quanto a conteúdo e extensão de direitos pode se resolver do ponto de vista de estratégia constitucional, por uma especificação incompleta, que dá lugar, justamente, à obtenção do consenso possível, já no plano de detalhamento, de descenso na hierarquia de decisões normativas: “...when people diverge on some (relatively) high-level proposition, they might be able to agree when they attempt a conceptual descent and lower the level of abstraction". ${ }^{30}$ Para que tal esquema de legitimação das decisões, todavia, se revele adequado e eficaz, é indispensável que se mantenha o canal de comunicação com a cidadania aberto e alimentado; é preciso que a cidadania desenvolva em relação a essa definição de conteúdo de suas próprias garantias, um sentimento de pertença.

Na mesma linha, caminha Zagrebelsky ${ }^{31}$ destacando às constituições democráticas como “...una propuesta de soluciones y coexistencias posibles...", única compreensão que conferiria a esse documento fundante, a abertura necessária a comportar a espontaneidade da vida social e a competição para a assunção da direção política. A busca, todavia, dos caminhos de concretização desse "...compromiso de las posibilidades..."; a identificação daquilo que, naquele momento, seja o desejável, como manifestação de política constitucional, é um processo que há de pressupor uma cidadania mais ativa - menos "sedada" pelo discurso da já consecução e garantia de soluções dos temas que lhe são mais próximos, a saber, direitos fundamentais.

Num plano mais inserido no cotidiano dos integrantes do corpo social, também o discurso pacificador já tanto mencionado, determina um alheamento da cidadania em relação ao processo de planejamento do agir do poder, especialmente no campo da formulação, implementação e controle das políticas públicas, que parecem se colocar como mero consectário de uma escolha e priorização já feita, e que se apresentaria dissociada de qualquer avaliação de possibilidades concretas de cada momento. Assim, iniciativas como orçamento participativo, ou outras assemelhadas, que permitam um acompanhamento mais próximo do agir do poder que concretiza direitos fundamentais se tornam a exceção -

${ }^{29}$ GOYARD-FABRE, Simone. Os princípios filosóficos do direito político moderno, p. 337.

30 SUNSTEIN, Cass. Constitutional agreements without constitutional theories. Ratio Juris, p. 117-130.

31 ZAGREBELSKY, Gustavo. El derecho dúctil. Ley, derechos, justicia, p. 14 
quando deveriam ser a regra.

Não se pode deixar de ter em conta que contribui para esse alheamento, a democracia “...meramente representacional..." que se vive, em que a ausência de uma formação cívico-democrata funciona como elemento de bloqueio às iniciativas populares de interferência, reforma ou regeneração do sistema. ${ }^{32}$ Afinal, uma cidadania que não conhece ou não responde às iniciativas, é fruto de um ambiente que não tem clareza no que seja democrático - para o que, decerto, contribui esse sentimento de que todas as grandes decisões já se empreenderam, e através do sacrossanto instrumento da Constituição.

Destaque-se que o debate com a cidadania, seja na dimensão mais abstrato da identificação do conteúdo dos direitos, seja na sua tradução em prioridades e políticas públicas, haveria de ser - a rigor - permanente, na medida em que o sentido constitucional se constitui realidade sempre temporalmente relacionada. Asseverar-se que o leque de direitos já resta definido, e admite sempre a melhor concretização pelo exercício do controle jurídico promovido por instituições controladoras, é caminhar como já sublinhava Osório ${ }^{33}$ no sentido da corrosão insidiosa das bases de legitimação democrática.

Em síntese, o direito, destinado que é à regulação do dever ser no corpo social, exige um permanente diálogo com esse seu destinatário. É de Martín-Rebollo ${ }^{34}$ a advertência de que se o direito é irreal no cotejo com o tecido social, por mais bem intencionado que seja, estará fadado ao descumprimento.

Um direito que se afirma valorativamente comprometido, é aquele que se encontra em permanente processo de aprimoramento, numa relação de troca com os seus operadores. Um direito axiológico não tem pretensão de deter em si todas as soluções - ao contrário, ele consulta permanentemente a seus destinatários, cujo depoimento há de ser o único que interessa para a apuração de suas eventuais virtudes. Um direito

\footnotetext{
32 No tema, consulte-se RUBIO CARRACEDO, José. Ciudadanos sin democracia. Nuevos ensayos sobre cidadanía ética y democracia. Granada: Comares, 2005, p. 3.

${ }^{33}$ Interessante o registro do autor, de outra faceta da pretensão de auto-suficiência do direito, que faz repousar nos meios e órgãos de controle jurídico, uma "...condição de instâncias superiores, lugar cultivado e cultuado, onde a aura de moralidade e sensibilidade social acaba por coroar individualmente seus membros, e corroer invisivelmente as bases institucionais de legitimação democrática" (OSÓRIO, Fábio Medina. O "novo" sistema judicial brasileiro: significados e significantes. In: OSÓRIO, Fábio Medina; SOUTO, Marcos Juruena Villela. Direito administrativo: estudos em homenagem a Diogo de Figueiredo Moreira Neto, p. 59-107)

${ }^{34}$ MARTÍN-REBOLLO. Para qué sirve el derecho? Una reflexión sobre el derecho público en la sociedad contemporánea. In: OSÓRIO, Fábio Medina; SOUTO, Marcos Juruena Villela. Direito administrativo: estudos em homenagem a Diogo de Figueiredo Moreira Neto, p. 177-194.
} 
valorativo caminha na trilha da formação de relações de confiança, lutando contra as reações funcionais do descrédito como o paternalismo, o providencialismo e o excesso de litigiosidade. ${ }^{35} \mathrm{Um}$ direito que quebra o isolamento cognitivo e interage, se re-legitima permanentemente, e nisso ganha a sua efetividade.

A pretensão de garantia, portanto, a direitos fundamentais, não pode repousar em um direito narcisista, isolado na ilusão de sua própria figura. O Direito-Narciso, instrumental a essa mesma finalidade, quebrado o encanto da auto-imagem, haverá de consolidar sua relação de encantamento com uma nova ninfa: a cidadania.

\section{Referências}

ABRAMOVICH, Victor; COURTIS, Christian. Los derechos sociales como derechos exigibles. Madrid: Trotta, 2002.

BARBOSA MOREIRA, José Carlos. O problema da duração dos processos: premissas para uma discussão séria. Revista Magister de Direito Civil e Processual Civil, n. 12, p. 27-36, maio/ jun. 2006.

BOBBIO, Norberto. A era dos direitos. 19. reimp. Tradução de Carlos Nelson Coutinho. Rio de Janeiro: Campus, 1992. Traduzido de: L'età dei diritti.

CANOTILHO, J. J. Gomes. Estado pós-moderno e constituição sem sujeito. In: _ . "Brancosos" e interconstitucionalidade: itinerários dos discursos sobre a historicidade constitucional. Coimbra: Almedina, 2006.

CANOTILHO, J. J. Gomes. Romper ou rever com a constituição dirigente. In: ___ "Brancosos" e interconstitucionalidade: itinerários dos discursos sobre a historicidade constitucional. Coimbra: Almedina, 2006.

CLAM, Jean. A autopoiese no Direito. In: ROCHA, Leonel Severo; SCHWARTZ, Germano; CLAM, Jean. Introdução à teoria do sistema autopoiético do direito. Porto Alegre: Livr. do Advogado, 2005.

FARIA, José Eduardo. Introdução: o Judiciário e o desenvolvimento sócio-econômico. In: (Org.). Direitos humanos, direitos sociais e justiça. 1. ed., 4. tir. São Paulo: Malheiros, 2005.

FLEINER-GERSTER, Thomas. Teoria geral do Estado. Tradução de Marlene Holzhausen. Rev. téc. Flávia Portella Puschel. São Paulo: Martins Fontes, 2006. Traduzido de: Allgemeine Staatslehre.

GOYARD-FABRE, Simone. Os princípios filosóficos do direito político moderno. Tradução de Irene A. Paternot. São Paulo: Martins Fontes, 1999. Traduzido de: Les príncipes philosophiques du droit politique moderne.

HECLO, Hugh. Issue networks and the executive establishment. In: THEODOULOU, Stella Z.; CAHN, Matthew A. Public policy: the essential readings. USA: Prentice Hall Inc., 1995.

HOLMES, Stephen; SUNSTEIN, Cass. The cost of rights: why liberty depends on taxes. New York: W. W. Norton, 1999.

\footnotetext{
35 Sobre a substituição funcional à relação de confiança, consulte-se SZTOMPKA, Piotr. Trust. A sociological theory. USA: Cambridge University Press, 1999. p. 115-118.
} 
MARTÍN-REBOLLO, Luís. Para qué sirve el derecho? Una reflexión sobre el derecho público en la sociedad contemporánea. In: OSÓRIO, Fábio Medina; SOUTO, Marcos Juruena Villela. Direito administrativo: estudos em homenagem a Diogo de Figueiredo Moreira Neto. Rio de Janeiro: Lúmen Juris, 2006.

MENDES, Aluísio Gonçalves de Castro. Ações coletivas no direito comparado e nacional. São Paulo: R. dos Tribunais, 2002.

NEVES, Marcelo. A força simbólica dos direitos humanos. Revista Eletrônica de Direito do Estado, Salvador, Instituto de Direito Público da Bahia, n. 4, out./dez. 2005. Disponível em: <http://www.direitodoestado.com.br>. Acesso em: 30 mar. 2007.

ORDÓÑEZ SOLÍS, David. La protección judicial de los derechos fundamentales de solidariedad: derecho sociales, medio ambiente y consumidores. Granada: Comares, 2006.

OSÓRIO, Fábio Medina. O "novo” sistema judicial brasileiro: significados e significantes. In: OSÓRIO, Fábio Medina; SOUTO, Marcos Juruena Villela. Direito administrativo: estudos em homenagem a Diogo de Figueiredo Moreira Neto. Rio de Janeiro: Lúmen Juris, 2006.

PEÑA FREIRE, Antonio Manuel. La garantia en el Estado constitucional de derecho. Madrid: Trotta, 1997.

POZZOLO, Susanna. Un constitucionalismo ambiguo. In: CARBONELL, Miguél. (Ed.). Neoconstitucionalismo(s). Madrid: Trotta, 2003.

SUNSTEIN, Cass. Constitutional agreements without constitutional theories. Ratio Juris, v. 13, n. 1, p. 117-130, Mar. 2000.

SUNSTEIN, Cass. Republic.com. New Jersey: Princeton University Press, 2001.

VALLE, Vanice Lírio do. Diálogo institucional como pressuposto da efetividade constitucional. $A E^{2} C$ - Revista de Direito Administrativo e Constitucional, ano 6, n. 23, p. 189-206, jan./ mar. 2006.

VALLE, Vanice Lírio do. Mandado de injunção: a construção de uma garantia constitucional. Rio de Janeiro: Lúmen Juris, 2005.

ZAGREBELSKY, Gustavo. El derecho dúctil. Ley, derechos, justicia. 5. ed. Tradução de Marina Gascón. Madrid: Trotta, 2003. Traduzido de: Il diritto mitte. Legge, diritti, giustizia.

Informação bibliográfica deste texto, conforme a NBR 6023:2002 da Associação Brasileira de Normas Técnicas (ABNT):

VALLE, Vanice Lírio do. O direito-narciso - nova ameaça à jusfundamentalidade dos direitos. A\&C Revista de Direito Administrativo e Constitucional, Belo Horizonte, ano 7, n. 28, p. 27-44, abr.jun. 2007. 